\title{
Optimization of Zinc Recovery from Sphalerite Using Response Surface Methodology and Particle Swarm Optimization
}

\author{
Okechukwu D. Onukwuli', Ikechukwu A. Nnanwube ${ }^{2 *}$ \\ ${ }^{1}$ Department of Chemical Engineering, Faculty of Engineering, Nnamdi Azikiwe University, P. M. B. 5025, 420007 Awka, Nigeria \\ 2 Department of Chemical Engineering, Faculty of Engineering, Madonna University, No. 1 Madonna University Road, \\ 402105 Akpugo, Enugu, Nigeria \\ * Corresponding author, e-mail: nnanwube@madonnauniversity.edu.ng
}

Received: 20 January 2021, Accepted: 12 April 2021, Published online: 24 August 2021

\begin{abstract}
Hydrometallurgical leaching process has been identified as a viable procedure for recovering metals of value from their matrices. The optimization of zinc recovery from sphalerite in nitric acid solution was carried out in this study. The Central Composite Rotatable Design (CCRD) of Response Surface Methodology (RSM) and Particle Swarm Optimization (PSO) tool in matlab were deployed for the optimization studies. RSM modeling gave optimum conditions of $73.0^{\circ} \mathrm{C}$ leaching temperature, $3.48 \mathrm{M}$ acid concentration, $0.027 \mathrm{~g} / \mathrm{mL}$ solid/liquid ratio, $411.02 \mathrm{rpm}$ stirring rate, and 82.82 minutes leaching time; with a zinc yield of $87.67 \%$. With PSO, about $86.9 \%$ zinc was recovered at a leaching temperature of $69.1{ }^{\circ} \mathrm{C}$, acid concentration of $1.8 \mathrm{M}$, solid/liquid ratio of $0.031 \mathrm{~g} / \mathrm{mL}$, stirring rate of 270 rpm and leaching time of 85 minutes. Thus, PSO and RSM proved to be good optimization tools.
\end{abstract}

Keywords

sphalerite, nitric acid, leaching, Response Surface Methodology (RSM), Particle Swarm Optimization (PSO)

\section{Introduction}

Sulphide minerals are one of the most important sources of valuable metals such as gold, silver, copper, zinc et cetera. Due to the strong sulphur binding to these minerals, metals are usually extracted by pyrometallurgical or hydrometallugical route with chemical oxidation. Of these, hydrometallurgy apparently has a lower environmental impact, which has received increased attention in the last decades. Hydrometallurgical process has also been found to be suitable for lower grade ores and relatively small deposits [1].

Sphalerite $(\mathrm{ZnS})$ is a common and widely distributed sulphide mineral. It comes in association with other minerals such as galena $(\mathrm{PbS})$, pyrite $\left(\mathrm{FeS}_{2}\right)$, chalcopyrite $\left(\mathrm{CuFeS}_{2}\right)$, calcite $\left(\mathrm{CaCO}_{3}\right)$, dolomite $\left(\mathrm{CaCO}_{3} \cdot \mathrm{MgCO}_{3}\right)$, quartz $\left(\mathrm{SiO}_{2}\right)$, greenockite $(\mathrm{CdS})$, and barite $\left(\mathrm{BaSO}_{4}\right)$. Sphalerite can be deposited in veins, fractures, and cavities, or it can form as mineralizations or replacements of its host rock. Sphalerite often contains trace to minor amounts of cadmium, indium, germanium or gallium. These rare elements are valuable and when abundant enough can be recovered as profitable by-products. Minor amounts of manganese and arsenic can also be present in sphalerite [2].
Sphalerite is mainly used for the extraction of zinc, the fourth most common metal in use, trailing only iron, aluminium, and copper in annual production. The relative reactivity of zinc and its ability to attract oxidation to itself makes it an efficient sacrificial anode in cathodic protection. For example, cathodic protection of a buried pipeline can be achieved by connecting anodes made from zinc to the pipe. Zinc acts as the anode (negative terminus) by slowly corroding away as it passes electric current to the steel pipeline. Zinc is also used to cathodically protect metals that are exposed to sea water from corrosion [3]. The recovery of zinc from sphalerite has been carried out using organic and inorganic acids such as acetic acid [1], hydrochloric acid [4], sulpuric acid [5], and nitric acid [6], with varying percentages of zinc recovery. The leaching of sphalerite in nitric acid solution leads to the formation of zinc nitrate, nitrogen dioxide, water and elemental sulphur, as previously reported by Adebayo et al. [7] and illustrated in Eq. (1).

$$
\mathrm{ZnS}_{(\mathrm{s})}+4 \mathrm{HNO}_{3(\mathrm{aq})} \rightarrow \mathrm{Zn}\left(\mathrm{NO}_{3}\right)_{2(\mathrm{aq})}+2 \mathrm{NO}_{2(\mathrm{~g})}+2 \mathrm{H}_{2} \mathrm{O}_{(\mathrm{l})}+\mathrm{S}_{(\mathrm{s})}^{0}
$$


The Response Surface Methodology (RSM) model has been known as a powerful tool for optimization in several fields such as chemical engineering process and chemical analysis among many other applications [8]. The most popular RSM is the Central Composite Design (CCD). A CCD has three groups of design points:

1. two-level factorial or fractional factorial design points,

2. axial points (star points),

3. and center points.

CCDs are designed to estimate the coefficients of a quadratic model. Another important optimization tool that has become the focus of research in recent years is the Particle Swarm Optimization (PSO). PSO has become preferred for solving complex problems due to its advantages such as its simple principle, few parameters, and fast convergence speed [9]. Research on PSO mainly focuses on four aspects such as parameters setting, selection of neighborhood topology, improvement of learning strategy and hybridization of PSO with other algorithms $[10,11]$.

A number of authors have reported on the optimization of sphalerite leaching using RSM. However, studies on the optimization of the leaching process in nitric acid solution has not been reported. Guler [12] reported on the modeling and optimization of pressure acid leaching of sphalerite concentrate by RSM using oxygen under pressure in sulphuric acid solution. Nnanwube et al. [13, 14] reported on the modeling and optimization of zinc recovery from sphalerite in binary solutions of acetic acid/hydrogen peroxide and acetic acid/sodium nitrate, respectively. Nnanwube and Onukwuli [15], however, reported on the modeling and optimization of zinc recovery from Enyigba sphalerite in a binary solution of hydrochloric acid and hydrogen peroxide. Sobouti et al. [16], applied PSO in optimizing lead recovery from its concentrate using fluoroboric acid. Hence, in this work, the optimization of sphalerite leaching in nitric acid solution is reported. The optimization tools of RSM and PSO were used to determine the optimum conditions for zinc recovery.

\section{Materials and methods}

\subsection{Materials}

The sphalerite ore used as samples in this study was mined from the mines of Enyigba in Ebonyi State of Nigeria. The ore sample was crushed, ground to powder, and then sieved with ASTM standard test sieve to a particle size of $<75 \mu \mathrm{m}$. The mineralogical analysis of the ore was performed with ARL X'TRA Diffractometer. The result as previously reported [1] shows that the ore sample comprises mainly sphalerite and cerium germanium sulphide with major peaks at $30.15,28.56,47.50,43.16$ and $26.03^{\circ}$ $2 \theta$, respectively, as shown in Fig. 1. The chemical composition analysis of the sphalerite sample was carried out using X-supreme 600 model from Oxford Instruments. The result show the major oxides contained in the ore as $\mathrm{ZnO}(31.67 \%), \mathrm{SO}_{3}(29.81 \%), \mathrm{Na}_{2} \mathrm{O}(16.32 \%)$, and $\mathrm{Fe}_{2} \mathrm{O}_{3}$ $(11.95 \%)$ while the minor oxides are $\mathrm{SiO}_{2}(4.66 \%), \mathrm{MgO}$ (0.61\%), $\mathrm{Al}_{2} \mathrm{O}_{3}(1.66 \%), \mathrm{CaO}(2.01 \%)$ and $\mathrm{MnO}(1.03 \%)$. Oxides such as $\mathrm{Cr}_{2} \mathrm{O}_{3}(0.01 \%), \mathrm{TiO}_{2}(0.05 \%)$ and $\mathrm{P}_{2} \mathrm{O}_{5}$ $(0.08 \%)$ however occurred as traces. The result shows that the sphalerite ore used in this study exists mainly as $\mathrm{ZnS}$ $(61.48 \%)$. The result of the chemical composition analysis of the sphalerite is presented in Table 1.

\subsection{Experimental procedure}

The leaching experiments were performed in atmospheric conditions on a constant-temperature magnetic stirrer with the aid of a $500 \mathrm{~mL}$ flask. Leaching agent at a predetermined concentration was added to the beaker and stirring was initiated. A predetermined amount of sphalerite was added when the temperature of the leachant reached the set value. A condenser was used to prevent solution loss by evaporation during the reaction. The leaching progress is indicated by the leaching rate of zinc from the sphalerite. At the end of each experiment stirring was stopped and the pregnant leach solution was filtered through whatman filter paper with the aid of a funnel. The resulting solution was diluted and analyzed for zinc with an Atomic Absorption Spectrophotometer (AAS) [13, 17, 18].

\subsection{AAS analysis}

AAS analysis was carried out using 240FS AA model from Agilent Technologies, according to the method of American Public Health Association (APHA) 1995.

Procedure: The sample was mixed thoroughly by shaking; $100 \mathrm{~mL}$ of the sample was poured into a $250 \mathrm{~mL}$ beaker, to which $5 \mathrm{~mL}$ of concentrated nitric acid was added and heated to boil till the volume was reduced to about $15-20 \mathrm{~mL}$, by adding concentrated nitric acid in increments of $5 \mathrm{~mL}$ till all the residue was completely dissolved. The mixture was cooled, transferred and made up to $100 \mathrm{~mL}$ using metal-free distilled water. The sample was aspirated into the oxidizing air-acetylene flame. When the aqueous sample was aspirated, the sensitivity for $1 \%$ absorption was observed. The reference solution 


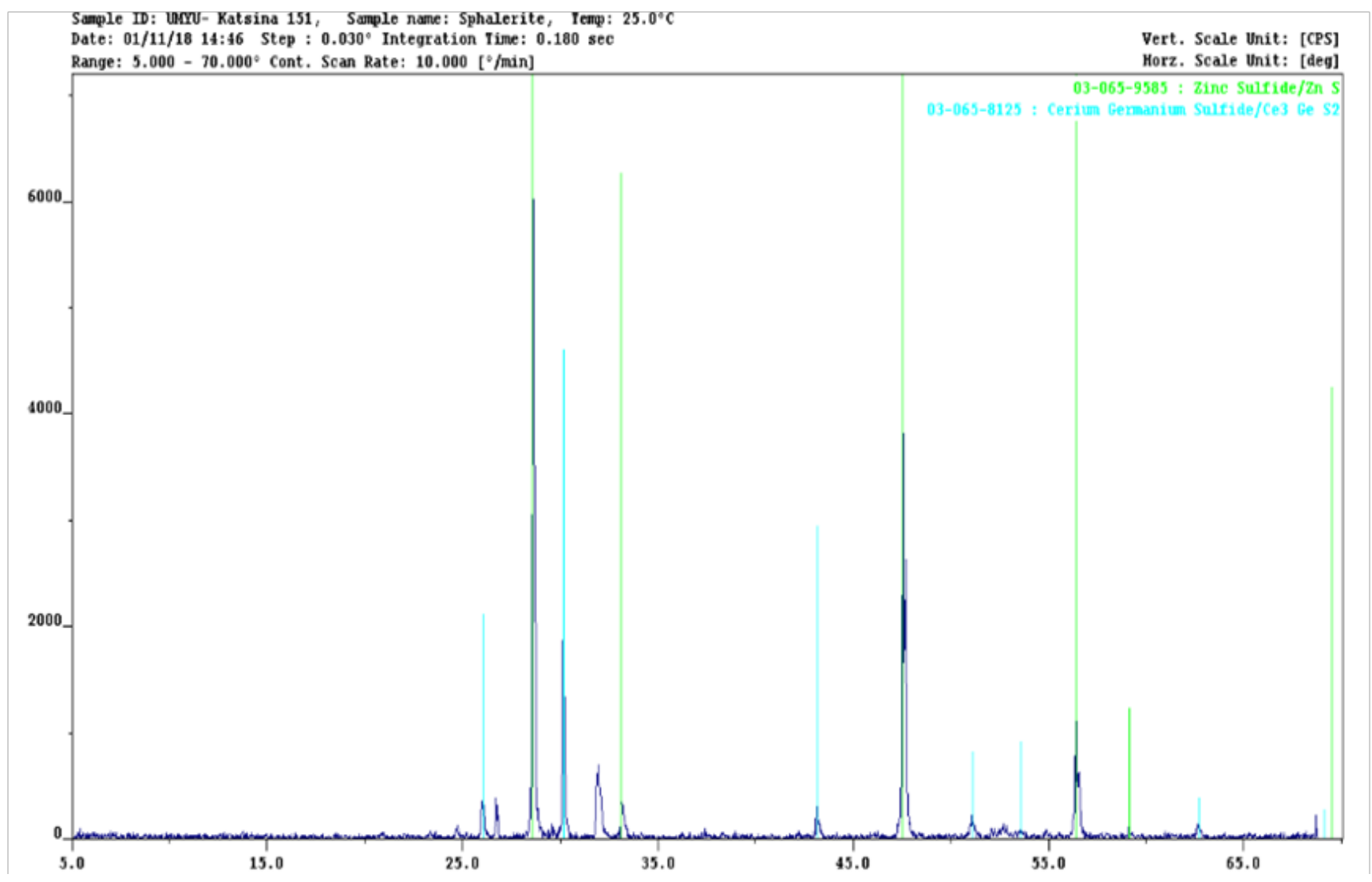

Fig. 1 X-ray diffraction pattern of Enyigba sphalerite

Table 1 Result of chemical composition analysis of sphalerite

\begin{tabular}{lccc}
\hline Component & Percentage (\%) & Component & Percentage (\%) \\
\hline $\mathrm{SiO}_{2}$ & 4.66 & $\mathrm{MgO}$ & 0.61 \\
$\mathrm{TiO}_{2}$ & 0.05 & $\mathrm{CaO}$ & 2.01 \\
$\mathrm{Al}_{2} \mathrm{O}_{3}$ & 1.66 & $\mathrm{Na}_{2} \mathrm{O}$ & 16.32 \\
$\mathrm{Fe}_{2} \mathrm{O}_{3}$ & 11.95 & $\mathrm{P}_{2} \mathrm{O}_{5}$ & 0.08 \\
$\mathrm{Cr}_{2} \mathrm{O}_{3}$ & 0.01 & $\mathrm{SO}_{3}$ & 29.81 \\
$\mathrm{ZnO}$ & 31.67 & $\mathrm{Cl}$ & 0.14 \\
$\mathrm{MnO}$ & 1.03 & & \\
\hline
\end{tabular}

was prepared daily by diluting the single stock zinc solution (which had been prepared in the optimum concentration range) with water containing $1.5 \mathrm{~mL}$ concentrated nitric acid per litre. A calibration blank was prepared using all the reagents except for the metal stock solution. Calibration curve for zinc was prepared by plotting the absorbance of standard versus zinc concentration [1].

\subsection{Chemical composition analysis by XRF}

Sample preparation was carried out using the following procedure:

- About $20 \mathrm{~g}$ of samples were dried and sieved through $2 \mathrm{~mm}$ sieves. Samples were milled further to between 20-53 $\mu \mathrm{m}$. About $5 \mathrm{~g}$ homogenous specimen of the sample was loaded into special XRF cups prepared with $4 \mu \mathrm{m}$ ultralene film or $4 \mu \mathrm{m}$ prolene film. The cups were half-full with sample [2].

Sample measurement was carried out using the following procedure:

- The instrument was switched on and taken to measurement mode. The measurement software was opened and the desired method selected. The sample was placed on the instrument in its bench top measurement position setup and covered. The sample compartment lid was closed to prevent scattering $\mathrm{X}$-ray radiation. The measurement conditions were set. Two sets of measurement conditions were run at $40 \mathrm{kV}$ for element $\mathrm{Ti}$ (22) and above followed by $15 \mathrm{kV}$ for elements from $\mathrm{Mg}$ to $\mathrm{Zn}$. Time for each condition is set by user. The sample details were entered. The trigger was pulled to start the measurement. Measurement of complete spectrum takes 60 to 120 seconds per sample and all detectable elements were measured simultaneously. Raw qualitative spectra and quantified result were then stored in the software [2]. 


\subsection{Design of experiment}

In this study, a fractional Central Composite Design (CCD) of Response Surface Methodology (RSM) was used for optimization of the leaching process. The leaching temperature, acid concentration, solid/liquid ratio, stirring rate, and leaching time were chosen as the independent variables, while zinc yield was the dependent variable.

The RSM based optimization was carried out using Design Expert 10.0 software (Stat Ease Inc., Minneapolis, USA). The Central Composite Design (CCD) for optimization of zinc recovery from sphalerite with the variables and their respective coded levels are depicted in Table 2. The experimental design is presented in Table 3. The coding of the variables was done using Eq. (2):

$x_{i}=\frac{X_{i}-X_{m}}{\Delta X_{i}}$

where $x_{i}$ is the dimensionless value of the independent variable, $X_{i}$ is the real value of the independent variable, $X_{m}$ is the real value of the independent variable at the midpoint and $\Delta X_{i}$ is the step change of the real value corresponding to a variation of a unit for the dimensional value of the variable $i=1,2,3, \ldots k$.

The response variable was fitted by a sufficient model, which is able to describe the relationship between the dependent output variable and the independent variables. The regression model is shown in Eq. (3) [19, 20]:

$$
Y=\beta_{0}+\sum_{k=1}^{q} \beta_{k} x_{k i}+\sum_{k=1}^{q-1} \sum_{l=k+1}^{q} \beta_{k l} x_{k i} x_{l i}+\sum_{k=1}^{q} \beta_{k k} x_{k i}^{2}+\varepsilon_{i},
$$

where $Y$ is the response representing zinc yield, $\beta_{0}$ is the intercept coefficient; $\beta_{k}, \beta_{k k}$ and $\beta_{k l}$ are interaction coefficients of linear, quadratic and second order terms of model respectively; $x_{k i}$ and $x_{l i}$ are process variables ( $k$ and $l$ range from 1 to $q$ ); $q$ is the number of independent parameters

Table 2 Levels and range of variables tested in fractional CCD

\begin{tabular}{lccccccc}
\hline $\begin{array}{l}\text { Independent } \\
\text { variable }\end{array}$ & Unit & Symbol & & & & \\
& & & $-\alpha$ & -1 & 0 & +1 & $+\alpha$ \\
\hline $\begin{array}{l}\text { Leaching } \\
\text { temperature }\end{array}$ & ${ }^{\circ} \mathrm{C}$ & $A$ & 35 & 50 & 65 & 80 & 95 \\
$\begin{array}{l}\text { Acid } \\
\text { concentration }\end{array}$ & $\mathrm{M}$ & $B$ & 0.25 & 1.5 & 2.75 & 4.0 & 5.25 \\
$\begin{array}{l}S / L \text { ratio } \\
\text { Stirring rate }\end{array}$ & $\mathrm{g} / \mathrm{mL}$ & $C$ & 0.01 & 0.02 & 0.03 & 0.04 & 0.05 \\
Leaching time & $\mathrm{rpm}$ & $D$ & 100 & 250 & 400 & 550 & 700 \\
\hline
\end{tabular}

and $\varepsilon_{i}$ is the error. The final equation for five independent parameters $(q)$ with the error term is given by Eq. (4):

$$
\begin{aligned}
& Y=\beta_{0}+\beta_{1} x_{1}+\beta_{2} x_{2}+\beta_{3} x_{3}+\beta_{4} x_{4}+\beta_{5} x_{5}+\beta_{12} x_{1} x_{2} \\
& +\beta_{13} x_{1} x_{3}+\beta_{14} x_{1} x_{4}+\beta_{15} x_{1} x_{5}+\beta_{23} x_{2} x_{3}+\beta_{24} x_{2} x_{4} \\
& +\beta_{25} x_{2} x_{5}+\beta_{34} x_{3} x_{4}+\beta_{35} x_{3} x_{5}+\beta_{45} x_{4} x_{5}+\beta_{11} x_{1}^{2} \\
& +\beta_{22} x_{2}^{2}+\beta_{33} x_{3}^{2}+\beta_{44} x_{4}^{2}+\beta_{55} x_{5}^{2}+\varepsilon_{i} .
\end{aligned}
$$

The interactive effects of the independent variables on the dependent variable were illustrated by 3D response surface plots.

\section{Results and discussion}

\subsection{Statistical analysis}

The recovery of zinc from Enyigba sphalerite was optimized statistically using the Response Surface Methodology (RSM). The data generated from the Central Composite Design was analyzed using the Design Expert software 10.0. Mathematical relationship between the dependent variables and the independent variable was evaluated using the software. The statistical parameters computed for the selection of the best fitted model comprise the $p$-value, degrees of freedom, lack of fit, coefficient of determination $\left(R^{2}\right)$, coefficient of variation (C.V.), standard deviation and signal to noise ratio. By convention, the model with non-significant lack-offit $p$-value (and also not aliased) and highest $R^{2}$ value is normally selected.

The adequacy of the proposed model was tested using the Design-Expert sequential model sum of squares and the model summary statistics (Table 4). The significance of the model was tested using the analysis of variance (ANOVA) shown in Table 5. And from the statistics test, the regression coefficient $\left(R^{2}=0.9959\right)$ is high, and the adjusted $R^{2}(0.9884)$ is in close agreement with the predicted $R^{2}(0.9280)$ value as shown in Table 4. A model is considered significant if the $p$-value (significance probability value) is less than 0.05 . From the p-values presented in Table 5, it can be seen that the linear terms $A, B, C, D$, and $E$, and the quadratic terms $A^{2}, B^{2}, C^{2}, D^{2}$, and $E^{2}$ are significant model terms. Based on these considerations, the insignificant terms of the model are removed and model reduces to Eq. (5).

$$
\begin{aligned}
& \text { Yield }(\%)=85.16+3.67 \times A+3.41 \times B-3.38 \times C \\
& +3.25 \times D+3.70 \times E-2.37 \times A^{2}-2.25 \times B^{2} \\
& -2.02 \times C^{2}-2.35 \times D^{2}-1.86 \times E^{2}
\end{aligned}
$$


Table 3 The Central Composite Design for sphalerite dissolution in nitric acid

\begin{tabular}{|c|c|c|c|c|c|c|c|c|c|c|}
\hline \multirow{2}{*}{ Run } & \multicolumn{2}{|c|}{ Leaching temp. $\left({ }^{\circ} \mathrm{C}\right)$} & \multicolumn{2}{|c|}{ Acid conc. (M) } & \multicolumn{2}{|c|}{$S / L$ ratio $(\mathrm{g} / \mathrm{mL})$} & \multicolumn{2}{|c|}{ Stirring rate (rpm) } & \multicolumn{2}{|c|}{ Leaching time (min) } \\
\hline & Coded & Real & Coded & Real & Coded & Real & Coded & Real & Coded & Real \\
\hline 1 & +1 & 80 & +1 & 4 & -1 & 0.02 & +1 & 550 & -1 & 60 \\
\hline 2 & -1 & 50 & -1 & 1.5 & +1 & 0.04 & +1 & 550 & +1 & 120 \\
\hline 3 & -1 & 50 & -1 & 1.5 & +1 & 0.04 & -1 & 250 & -1 & 60 \\
\hline 4 & 0 & 65 & 0 & 2.75 & 0 & 0.03 & -2 & 100 & 0 & 90 \\
\hline 5 & -1 & 50 & +1 & 4 & +1 & 0.04 & -1 & 250 & +1 & 120 \\
\hline 6 & 0 & 65 & -2 & 0.25 & 0 & 0.03 & 0 & 400 & 0 & 90 \\
\hline 7 & +1 & 80 & -1 & 1.5 & v1 & 0.02 & -1 & 250 & -1 & 60 \\
\hline 8 & +1 & 80 & +1 & 4 & +1 & 0.04 & +1 & 550 & +1 & 120 \\
\hline 9 & 0 & 65 & 0 & 2.75 & 0 & 0.03 & 0 & 400 & 0 & 90 \\
\hline 10 & 0 & 65 & 0 & 2.75 & 0 & 0.03 & 0 & 400 & 0 & 90 \\
\hline 11 & +1 & 80 & -1 & 1.5 & -1 & 0.02 & +1 & 550 & +1 & 120 \\
\hline 12 & 0 & 65 & 0 & 2.75 & 0 & 0.03 & 0 & 400 & 0 & 90 \\
\hline 13 & +1 & 80 & +1 & 4 & +1 & 0.04 & -1 & 250 & -1 & 60 \\
\hline 14 & +1 & 80 & +1 & 4 & -1 & 0.02 & -1 & 250 & +1 & 120 \\
\hline 15 & -1 & 50 & -1 & 1.5 & -1 & 0.02 & -1 & 250 & +1 & 120 \\
\hline 16 & -1 & 50 & +1 & 4 & -1 & 0.02 & -1 & 250 & -1 & 60 \\
\hline 17 & 0 & 65 & +2 & 5.25 & 0 & 0.03 & 0 & 400 & 0 & 90 \\
\hline 18 & 0 & 65 & 0 & 2.75 & -2 & 0.01 & 0 & 400 & 0 & 90 \\
\hline 19 & 0 & 65 & 0 & 2.75 & 0 & 0.03 & 0 & 400 & -2 & 30 \\
\hline 20 & +1 & 80 & -1 & 1.5 & +1 & 0.04 & -1 & 250 & +1 & 120 \\
\hline 21 & 0 & 65 & 0 & 2.75 & 0 & 0.03 & 0 & 400 & 0 & 90 \\
\hline 22 & 0 & 65 & 0 & 2.75 & 0 & 0.03 & 0 & 400 & 0 & 90 \\
\hline 23 & -1 & 50 & +1 & 4 & -1 & 0.02 & +1 & 550 & +1 & 120 \\
\hline 24 & 0 & 65 & 0 & 2.75 & 0 & 0.03 & +2 & 700 & 0 & 90 \\
\hline 25 & -2 & 35 & 0 & 2.75 & 0 & 0.03 & 0 & 400 & 0 & 90 \\
\hline 26 & +2 & 95 & 0 & 2.75 & 0 & 0.03 & 0 & 400 & 0 & 90 \\
\hline 27 & 0 & 65 & 0 & 2.75 & +2 & 0.05 & 0 & 400 & 0 & 90 \\
\hline 28 & -1 & 50 & +1 & 4 & +1 & 0.04 & +1 & 550 & -1 & 60 \\
\hline 29 & -1 & 50 & -1 & 1.5 & -1 & 0.02 & +1 & 550 & -1 & 60 \\
\hline 30 & +1 & 80 & -1 & 1.5 & +1 & 0.04 & +1 & 550 & -1 & 60 \\
\hline 31 & 0 & 65 & 0 & 2.75 & 0 & 0.03 & 0 & 400 & +2 & 150 \\
\hline 32 & 0 & 65 & 0 & 2.75 & 0 & 0.03 & 0 & 400 & 0 & 90 \\
\hline
\end{tabular}

In terms of actual factors, the zinc yield is shown in Eq. (6).

Yield $(\%)=-64.22+1.80 \times$ Leaching temp.

$+11.46 \times$ Acid conc. $+827.04 \times S / L$ ratio

$+0.12 \times$ Stirring rate $+0.50 \times$ Leaching time

$-0.01 \times$ Leaching temp. ${ }^{2}-1.44 \times$ Acid conc. $^{2}$

$-20250.00 \times S / L$ ratio $^{2}-1.04 \mathrm{E}-004 \times$ Stirring $^{2}$ rate $^{2}$

$-2.07 \mathrm{E}-003 \times$ Leaching time $^{2}$

The Model $F$-value of 133.58 implies the model is significant. There is only a $0.01 \%$ chance that an $F$-value this large could occur due to noise. The residual row shows
Table 4 Model summary statistics

\begin{tabular}{lccccc}
\hline Source & $\begin{array}{c}\text { Std. } \\
\text { Dev. }\end{array}$ & $R$-Squared & $\begin{array}{c}\text { Adjusted } \\
R \text {-Squared }\end{array}$ & $\begin{array}{c}\text { Predicted } \\
R \text {-Squared }\end{array}$ & PRESS \\
\hline Linear & 4.56 & 0.7297 & 0.6777 & 0.6658 & 668.26 \\
2FI & 5.78 & 0.7331 & 0.4829 & -2.5906 & 7179.20 \\
Quadratic & 0.86 & 0.9959 & 0.9884 & 0.9280 & 143.91 \\
Cubic & 0.72 & 0.9985 & 0.9920 & 0.9369 & 126.09 \\
\hline
\end{tabular}

how much variation in the response is still unexplained while the lack of fit is the amount the model predictions miss the observations. The "Lack of Fit $F$-value" of 1.46 implies the Lack of Fit is not significant relative to the pure error. Non-significant lack of fit is good as it shows that the model is well fitted. The pure error is the amount 
Table 5 ANOVA for the quadratic model

\begin{tabular}{|c|c|c|c|c|c|}
\hline Source & $\begin{array}{l}\text { Sum of } \\
\text { Squares }\end{array}$ & Df & $\begin{array}{c}\text { Mean } \\
\text { Square }\end{array}$ & $F$-value & $\begin{array}{l}p \text {-value } \\
\text { Prob }>F\end{array}$ \\
\hline Model & 1991.22 & 20 & 99.56 & 133.58 & $<0.0001$ \\
\hline$A$ - Leaching temp. & 323.40 & 1 & 323.40 & 433.92 & $<0.0001$ \\
\hline$B$ - Acid conc. & 279.48 & 1 & 279.48 & 374.99 & $<0.0001$ \\
\hline$C-S / L$ ratio & 274.05 & 1 & 274.05 & 367.70 & $<0.0001$ \\
\hline$D$ - Stirring rate & 254.15 & 1 & 254.15 & 341.00 & $<0.0001$ \\
\hline$E$ - Leaching time & 327.82 & 1 & 327.82 & 439.85 & $<0.0001$ \\
\hline$A B$ & 1.50 & 1 & 1.50 & 2.01 & 0.1836 \\
\hline$A C$ & 0.46 & 1 & 0.46 & 0.61 & 0.4508 \\
\hline$A D$ & 2.18 & 1 & 2.18 & 2.92 & 0.1156 \\
\hline$A E$ & 0.60 & 1 & 0.60 & 0.81 & 0.3886 \\
\hline$B C$ & 0.031 & 1 & 0.031 & 0.041 & 0.8431 \\
\hline$B D$ & $\begin{array}{c}5.625 \mathrm{E}- \\
003\end{array}$ & 1 & $\begin{array}{c}5.625 \mathrm{E}- \\
003\end{array}$ & $\begin{array}{c}7.547 \mathrm{E}- \\
003\end{array}$ & 0.9323 \\
\hline$B E$ & 0.031 & 1 & 0.031 & 0.041 & 0.8431 \\
\hline$C D$ & 0.11 & 1 & 0.11 & 0.14 & 0.7137 \\
\hline$C E$ & 1.50 & 1 & 1.50 & 2.01 & 0.1836 \\
\hline$D E$ & 0.46 & 1 & 0.46 & 0.61 & 0.4508 \\
\hline$A^{2}$ & 165.46 & 1 & 165.46 & 222.00 & $<0.0001$ \\
\hline$B^{2}$ & 148.50 & 1 & 148.50 & 199.25 & $<0.0001$ \\
\hline$C^{2}$ & 120.29 & 1 & 120.29 & 161.39 & $<0.0001$ \\
\hline$D^{2}$ & 161.99 & 1 & 161.99 & 217.35 & $<0.0001$ \\
\hline$E^{2}$ & 101.75 & 1 & 101.75 & 136.53 & $<0.0001$ \\
\hline Residual & 8.20 & 11 & 0.75 & & \\
\hline Lack of Fit & 5.23 & 6 & 0.87 & 1.46 & 0.3462 \\
\hline Pure Error & 2.97 & 5 & 0.59 & & \\
\hline Cor Total & 1999.42 & 31 & & & \\
\hline
\end{tabular}

of difference between replicate runs, while the Cor Total shows the amount of variation around the mean of the observations. The model explains part of it, the residual explains the rest [14]. The coefficient of variation (C.V.) is the standard deviation expressed as a percentage of the mean. The C.V. value of 1.12 illustrate that the model can be considered reasonably reproducible [21]. The signal-tonoise ratio which is given as the value of the adequate precision is 42.205 as shown in Table 6 . It compares the range of the predicted values at the design points to the average prediction error. Ratios greater than 4 indicate adequate model discrimination $[13,22]$.

Table 6 Summary of the regression values

\begin{tabular}{lcccc}
\hline Std. Dev. & Mean & C.V. \% & PRESS & $\begin{array}{c}\text { Adeq. } \\
\text { Precision }\end{array}$ \\
\hline 0.86 & 77.02 & 1.12 & 143.91 & 42.205 \\
\hline
\end{tabular}

The experimental data were also analyzed to test the relationship between the experimental and predicted zinc yield as shown in Fig. 2. It can be seen from Fig. 2 that the data points on the plot were reasonably distributed near to the straight line, indicating a good relationship between the experimental and predicted values of the response, and that the underlying assumptions of the above analysis were appropriate. The result also suggests that the selected quadratic model was adequate in predicting the response variables for the experimental data [13].

\subsection{Response surface plots and contour plots}

The optimization of zinc recovery from sphalerite was performed for different leaching temperatures, acid concentration, solid/liquid ratio, stirring rate and leaching time to determine optimum conditions. The response, which is the yield of zinc was plotted against two factors while maintaining other factors at their central level. 3D response surface plots and contour plots were used to represent the effect of process parameters on zinc yield. Fig. 3 exhibit the influence of leaching temperature $(A)$, acid concentration $(B)$, solid/liquid ratio $(C)$, stirring rate $(D)$ and leaching time $(E)$ on zinc recovery where the significance of interactive variables was given in terms of response surface plots and contour plots. The five input variables considered were found to affect the zinc yield with $p<0.05$ individually. The interactive effect of the two interactive variables $B C, B D, B E, C D$, and $C E$ showed

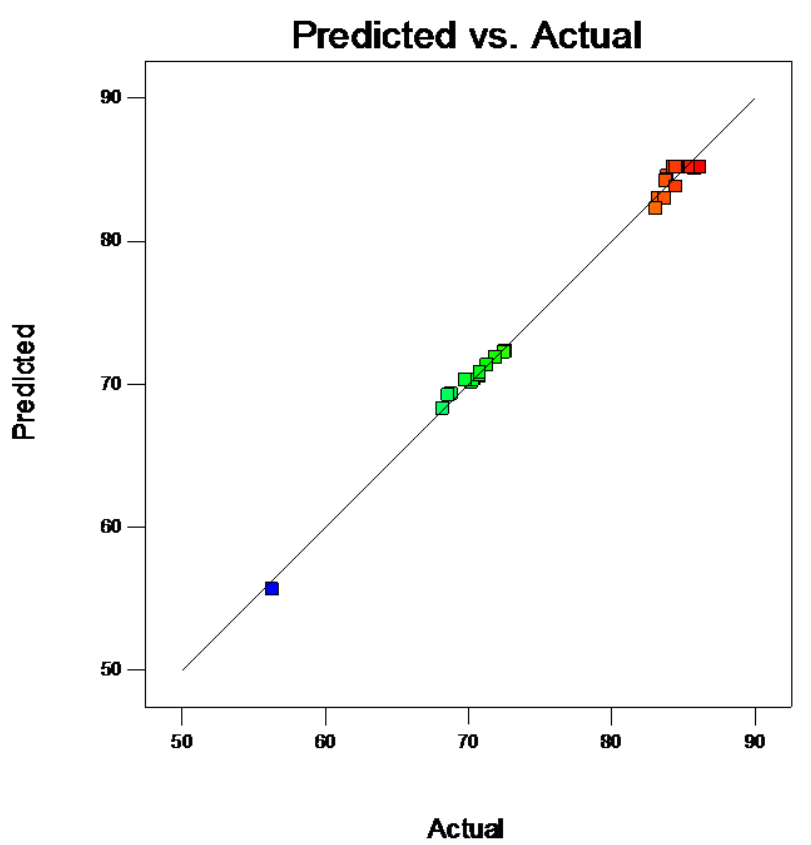

Fig. 2 Plot of predicted versus experimental values 
a positive effect, while $A B, A C, A D, A E$, and $D E$ showed a negative effect on zinc yield [15, 22].

From the quadratic effect of leaching temperature and acid concentration shown in Fig. 3 (a) and (e), the maximum zinc yields were recorded between the temperature range of $62-68{ }^{\circ} \mathrm{C}$ and acid concentration of 2.5-3 M. As the leaching temperature is increased, enough energy is made available for atomic and molecular collisions, and the interaction between the solute particles and the leachant increases the dissolution rate. Also, increasing the temperature increases the number of molecules whose kinetic energy is equal to or greater than activation energy, thus, increasing the dissolution rate [14].

As the acid concentration was increased beyond $3 \mathrm{M}$, and the leaching temperature also increased beyond $68{ }^{\circ} \mathrm{C}$, the percentage zinc recovery decreased. In the first instance, as the acid concentration increases and the rate of formation of the product increases, the amount of product gets to a saturation value near the solid particle and forms a solid product (elemental sulfur) layer around the particle, resulting in a decrease in dissolution rate [16]. This phenomenon may also indicate a change in the rate-determining step as the nitric acid concentration was increased beyong $3 \mathrm{M}$ [23]. In the second instance, the decrease in the percentage zinc recovery as the temperature was increased beyond $68^{\circ} \mathrm{C}$, may be due to the destruction of the ore structure at higher reaction temperature.

Fig. 3 (b) and (f) display the interactive effect of leaching temperature and solid/liquid ratio, with the figures showing that the process parameters were highly connected and had a quadratic effect. It was observed that the highest zinc yield was recorded within the solid/liquid ratio range of $0.03-0.035 \mathrm{~g} / \mathrm{mL}$ and leaching temperature range of $62-68{ }^{\circ} \mathrm{C}$. Hence, solid/liquid ratio had a mild effect on the zinc yield.

The interactive effect of leaching temperature and stirring rate is displayed in Fig. 3 (c) and (g). From the figures, higher zinc yield were recorded within a stirring rate range of 370-430 rpm and temperature range of $62-68{ }^{\circ} \mathrm{C}$. Fig. 3 (d) and (h) show the interactive effect of leaching temperature and leaching time. The figures show that the maximum zinc yield was recorded within the temperature range of $62-68{ }^{\circ} \mathrm{C}$ and leaching time range of $90-100$ minutes.

\subsection{Optimization of the leaching process via RSM and PSO}

The optimization tool in the Central Composite Design of RSM and PSO tool in matlab were deployed for the optimization study. Optimum conditions were predicted based on economic considerations [15]. Consequently, the software predicted optimum leaching conditions of $73.00{ }^{\circ} \mathrm{C}$ leaching temperature, $3.48 \mathrm{M}$ acid concentration, $0.027 \mathrm{~g} / \mathrm{mL}$ solid/liquid ratio, $411.02 \mathrm{rpm}$ stirring rate, and 82.82 minutes leaching time; with a zinc yield of $87.67 \%$. Experiments performed in triplicate to validate the results above gave an average zinc yield of $86.32 \%$. PSO optimization was carried out with the aid of a PSO algorithm developed in matlab software. The objective function for PSO optimization was developed in an M-file in matlab using Eq. (6). The five variables used for RSM optimization were used as decision variables for PSO. The upper and lower limits of the process variables were defined in the PSO algorithm. A swarm size of 30 was used while the number of iterations was set at 80 . Initial weight was set to be 1 while the initial weight damping ratio was set to be 0.99 . Personal learning coefficient was set at 1.2 while global learning coefficient was set to be 2.0. At the above conditions, the optimum conditions predicted by PSO include a leaching temperature of $69.1^{\circ} \mathrm{C}$, acid concentration of $1.8 \mathrm{M}$, solid/liquid ratio of $0.031 \mathrm{~g} / \mathrm{mL}$, stirring rate of $270 \mathrm{rpm}$ and leaching time of 85 minutes, at which about $86.87 \%$ zinc was predicted. Validation of predicted zinc yield was carried out by performing three experiments that gave an average value of $85.58 \%$ zinc recovery. The PSO plot for zinc yield is shown in Fig. 4. In RSM optimization, optimum points are chosen from several options based on economic considerations. Hence, the target is to minimize material usage as well as the leaching time. However, PSO is basically a minimization tool. It predicts the minimum possible values of the parameters for optimal metal recovery in the leaching process. The result showed a difference of $1.68 \mathrm{M}$ between the optimum acid concentrations obtained by RSM and PSO. This is partly compensated by the higher leaching time recorded by PSO. The result also shows that higher stirring rate did not play a very significant role in the leaching process as a difference of $141.02 \mathrm{rpm}$ was recorded in the optimum stirring rates obtained by RSM and PSO. Other parameters such as leaching temperature and solid/liquid ratio were found to have approximately the same optimum points in the two optimization methods. Compared to a previous kinetic study on the leaching of sphalerite in nitric solution [6] in which about $86.6 \%$ zinc was recovered, the result obtained from this study indicates that the two optimization techniques used are viable for zinc recovery from sphalerite. 


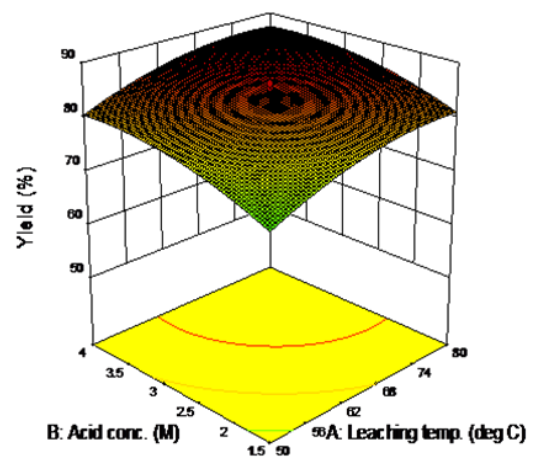

(a)

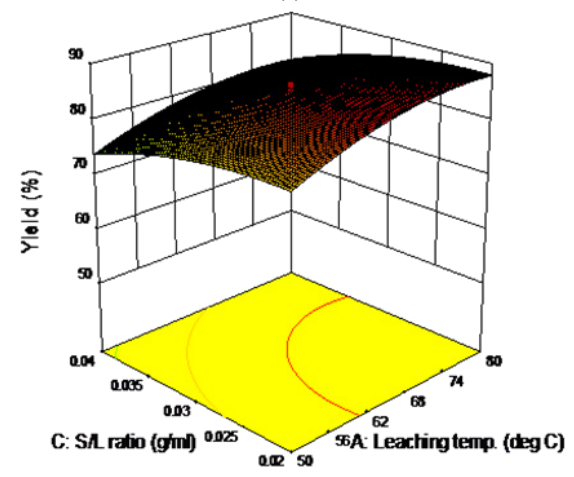

(b)

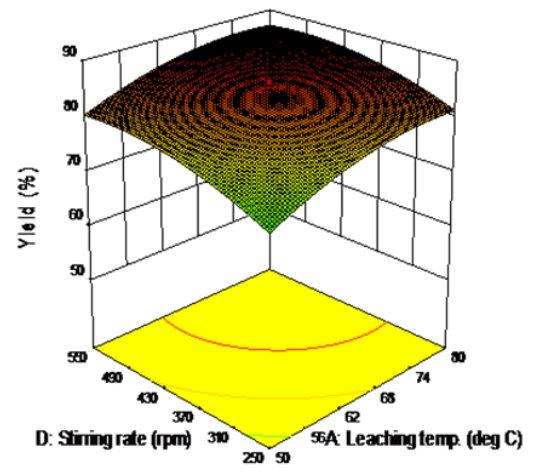

(c)

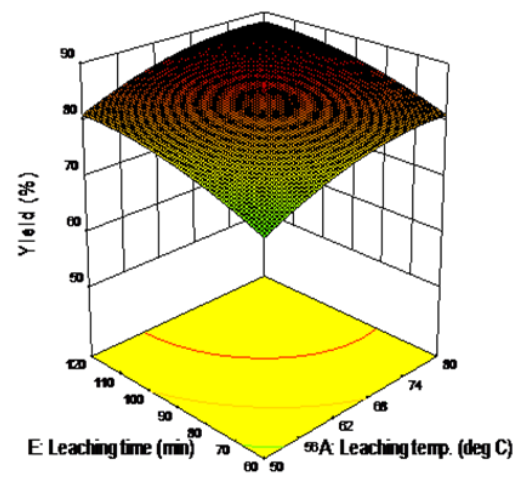

(d)

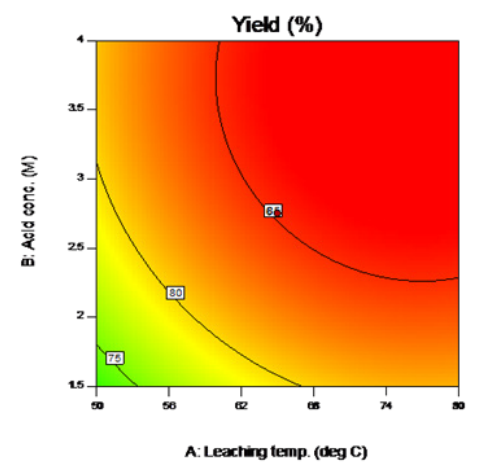

(e)

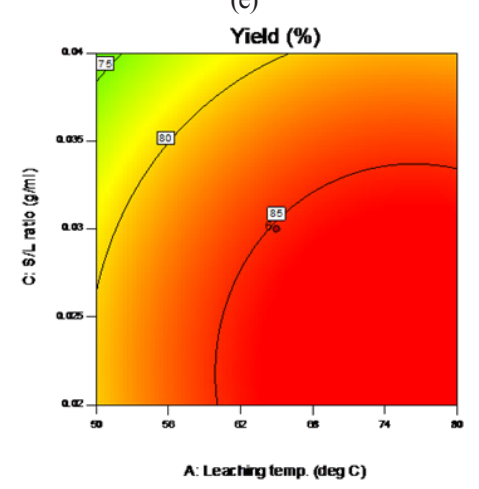

(f)

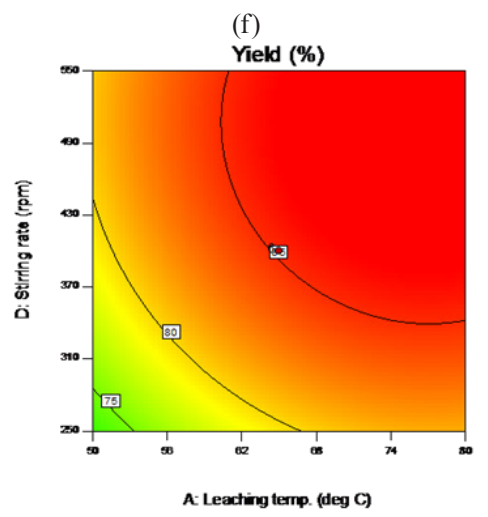

(g)

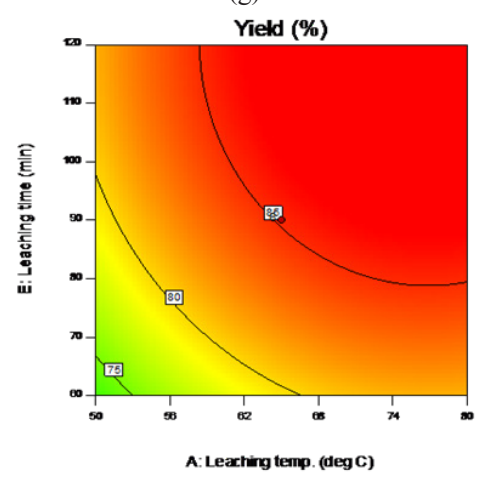

(h)

Fig. 3 3D response surface plots and contour plots on the effects of process variables on zinc yield; (a) response surface plot on the effect of leaching temperature and acid concentration on zinc yield, (b) response surface plot on the effect of leaching temperature and $S / L$ ratio on zinc yield,

(c) response surface plot on the effect of leaching temperature and stirring rate on zinc yield, (d) response surface plot on the effect of leaching temperature and leaching time on zinc yield, (e) contour plot on the effect of leaching temperature and acid concentration on zinc yield, (f) contour plot on the effect of leaching temperature and $S / L$ ratio on zinc yield, $(\mathrm{g})$ contour plot on the effect of leaching temperature and stirring rate on zinc yield, (h) contour plot on the effect of leaching temperature and leaching time on zinc yield 


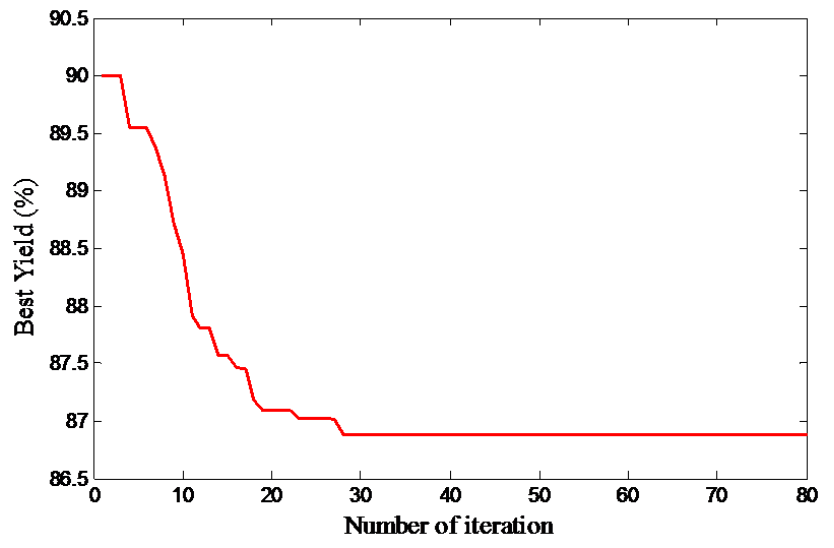

Fig. 4 Plot of zinc yield against number of iteration

\section{References}

[1] Nnanwube, I. A., Udeaja, J. N., Onukwuli, O. D. "Kinetics of zinc recovery from sphalerite in acetic acid solution", Journal of Materials and Environmental Sciences, 11(3), pp. 499-511, 2020. [online] Available at: https://www.jmaterenvironsci.com/ Document/vol11/vol11_N3/JMES-2020-1144-Nnanwube.pdf [Accessed: 19 February 2020]

[2] Nnanwube, I. A. "Kinetics and optimization studies on the hydrometallurgical recovery of zinc, lead, and alumina from their parent matrices", PhD Thesis, Nnamdi Azikiwe University, 2019.

[3] Bounoughaz, M., Salhi, E., Benzine, K., Ghali, E., Dalard, F. "A comparative study of the electrochemical behavior of Algerian zinc and a zinc from a commercial sacrificial anode", Journal of Materials Science, 38(6), pp. 1139-1145, 2003.

https://doi.org/10.1023/A:1022824813564

[4] Baba, A. A., Adekola, F. A. "Hydrometallurgical processing Nigerian sphalerite in hydrochloric acid: Characterization and dissolution kinetics", Hydrometallurgy, 101(1-2), pp. 69-75, 2010. https://doi.org/10.1016/j.hydromet.2009.12.001

[5] Hasani, M., Koleini, S. M. J., Khodadadi, A. "Kinetics of Sphalerite Leaching by Sodium Nitrate in Sulfuric Acid", Journal of Mining and Environment, 7(1), Serial Number 1, pp. 1-12, 2016. https://doi.org/10.22044/jme.2016.454

[6] Onukwuli, O.D., Nnanwube, I. A. "Hydrometallurgical Processing of a Nigerian Sphalerite Ore in Nitric Acid: Characterization and Dissolution Kinetics", The International Journal of Science and Technoledge, 6(3), pp. 40-54, 2018. [online] Available at: http://www.internationaljournalcorner.com/index.php/theijst/ article/view/129559/89882 [Accessed: 01 May 2018]

[7] Adebayo, A. O., Ipinmoroti, K. O., Ajayi, O. O. "Leaching of Sphalerite with Hydrogen Peroxide and Nitric Acid Solutions", Journal of Minerals \& Materials Characterization \& Engineering, 5(2), pp. 167-177, 2006.

https://doi.org/10.4236/jmmce.2006.52012

\section{Conclusions}

The optimization of zinc recovery from Enyigba sphalerite was undertaken in this work. A quadratic mathematical model obtained by RSM established optimal conditions for the recovery of zinc from sphalerite as leaching temperature of $73.00{ }^{\circ} \mathrm{C}$, acid concentration of $3.48 \mathrm{M}$, solid/liquid ratio of $0.027 \mathrm{~g} / \mathrm{ml}$, stirring rate of $411.02 \mathrm{rpm}$, and leaching time of 82.82 minutes; with a zinc yield of $87.67 \%$, which was validated as $86.32 \%$. PSO gave an optimum zinc yield of $86.87 \%$. Hence, RSM and PSO proved to be valuable optimization tools.

\section{Acknowledgements}

The authors are grateful to Dr. Ekwe Bassey for helping with the PSO algorithm.

[8] Esonye, C., Onukwuli, O. D., Ofoefule, A. U. "Optimization methyl ester production from Prunus Amygdalus seed oil response surface methodology and Artificial Neural Networks", Renewable Energy, 130, pp. 61-72, 2019.

https://doi.org/10.1016/j.renene.2018.06.036

[9] Li, Y., Zhan, Z-H., Lin, S., Zhang, J., Luo, X. "Competitive cooperative particle swarm optimization with information sharing mechanism for global optimization problems", Information Sciences, 293, pp. 370-382, 2015.

https://doi.org/10.1016/j.ins.2014.09.030

[10] Xu, G., Cui, Q., Shi, X., Ge, H., Zhan, Z-H., Lee, H. P., Liang, Y., Tai, R., Wu, C. "Particle swarm optimization based on dimensional learning strategy", Swarm and Evolutionary Computation, 45, pp. 33-51, 2019.

https://doi.org/10.1016/j.swevo.2018.12.009

[11] Tanweer, M. R., Suresh, S., Sundararajan, N. "Self regulating particle swarm optimization algorithm", Information Sciences, 294, pp. 182-202, 2015. https://doi.org/10.1016/j.ins.2014.09.053

[12] Guler, E. "Pressure Acid Leaching of Sphalerite Concentrate. Modeling and Optimization by Response Surface Methodology", Physicochemical Problems of Mineral Processing, 52(1), pp. 479-496, 2016. https://doi.org/10.5277/ppmp160139

[13] Nnanwube, I. A., Udeaja, J., Onukwuli, O. "Modeling and Optimization of Zinc Recovery from Enyigba Sphalerite in a Binary Solution of Acetic Acid and Hydrogen Peroxide", Sigma Journal of Engineering and Natural Sciences, 38(2), pp. 589-601, 2020. [online] Available at: https://eds.yildiz.edu.tr/AjaxTool/ GetArticleByPublished ArticleId? Published ArticleId=5097 [Accessed: 29 June 2020] 
[14] Nnanwube, I., Udeaja, J., Onukwuli, O., Ugonabo, V., Uwaleke, C. "Modeling and optimization of zinc recovery from sphalerite using response surface methodology", Maejo International Journal of Science and Technology, 14(03), pp. 283-292, 2020. [online] Available at: http://www.mijst.mju.ac.th/vol14/283-292.pdf [Accessed: 23 December 2020]

[15] Nnanwube, I., Onukwuli, O. "Modeling and optimization of galena dissolution in a binary solution of nitric acid and ferric chloride using artificial neural network coupled with genetic algorithm and response surface methodology", South African Journal of Chemical Engineering, 32, pp. 68-77, 2020. https://doi.org/10.1016/j.sajce.2020.03.001

[16] Sobouti, A., Hoseinian, F. S., Rezai, B., Jalili, S. "The lead recovery prediction from lead concentrate by an artificial neural network and particle swarm optimization", Geosystems Engineering, 22(6), pp. 319-327, 2019.

https://doi.org/10.1080/12269328.2019.1644205

[17] Ma, J., Tang, Y., Yang, D. Q., Pei, P. "Kinetics of advanced oxidative leaching of pyrite in a potassium peroxy-disulphate solution", Journal of the Southern African Institute of Mining and Metallurgy, 120(2), pp. 165-172, 2020. https://oi.org/10.17159/2411-9717/710/2020

[18] Kocan, F., Hicsonmez, U. "Leaching of Celestite in Sodium Hydroxide Solutions and Kinetic Modeling", Journal of Dispersion Science and Technology, 40(1), pp. 43-54, 2019. https://doi.org/10.1080/01932691.2018.1464466
[19] Venkatachalam, C. D., Sengottian, M., Ravichandran. S. R., Subramaniyan, K., Kalappan Thangamuttu, P. "Optimization Studies on Subcritical Water Extraction of Fuels and Fine Chemicals from Prosopis juliflora: An Invasive Weed Tree", Periodica Polytechnica Chemical Engineering, 65(1), pp. 105-115, 2021. https://doi.org/10.3311/PPch.15187

[20] Fülöp, V., Jakab, G., Tóth, B., Balogh, E., Antal, I. "Study on Optimization of Wet Milling Process for the Development of Albendazole Containing Nanosuspension with Improved Dissolution", Periodica Polytechnica Chemical Engineering, 64(4), pp. 401-420, 2020. https://doi.org/10.3311/PPch.15569

[21] Chen, G., Chen, J., Srinivasakannan, C., Peng, J. "Application of response surface methodology for optimization of the synthesis of synthetic rutile from titania slag", Applied Surface Science, 258(7), pp. 3068-3073, 2011.

https://doi.org/10.1016/j.apsusc.2011.11.039

[22] Nnanwube, I. A., Onukwuli, O. D., Ajana, S. U. "Modeling Optimization of Galena Dissolution In Hydrochloric Acid: Comparison of Central Composite Design and Artificial Neural Network", Journal of Minerals and Materials Characterization and Engineering, 6(3), pp. 294-315, 2018. https://doi.org/10.4236/jmmce.2018.63021

[23] Baba, A. A., Adekola, F. A. "Comparative analysis of the dissolution kinetics of galena in binary solutions of $\mathrm{HCl} / \mathrm{FeCl}_{3}$ and $\mathrm{HCl} / \mathrm{H}_{2} \mathrm{O}_{2}$ ", International Journal of Minerals, Metallurgy and Materials, 18(1), pp. 9-17, 2011. https://doi.org/10.1007/s12613-011-0393-1 